\title{
Albanon
}

Revistë kulturore

\section{Lundrimi i turbullt i kritikës së artit}

Shkrime të pabotuara të Sergio Bettini-t (1936-1977)

Michela Agazzi dhe Chiara Romanelli

\section{Relacion mbi inspektimin në Shqipëri}

Relacion mbi inspektimin e bërë me urdhër të Ministrisë së Arsimit në Krujë, Rubig, Balldren, Kakarriq, Shkodër, Elbasan, Korçë, Voskopojë, Mborje, Boboshticë,Vithkuq.

18 prill 1940

Arkivi Bettini, Shkrime të pabotuara, 102 (klasa 5/140)

Tekst i shkruajtur, 16 fletë

I redaktuar, firmosur dhe datuar

Datimi 18 prill 1940

\section{Krujë - Kalaja}

Përmasat e fortifikimi të vogël janë të lehta për t’u imagjinuar nga fragmentet murore të mbetura. Është e vështirë të dallohen pjesët e periudhës së Gjegj Kastriotit. Të kësaj periudhe mund të jetë bazamenti i kullës vrojtuese, e cila për një periudhë kohe është përdorur si kullë me këmbanë dhe se është e ndërtuar mbi një kullë të mëparshme të madhe gjysmërrethore. E së njejtës kohë mund të jetë porta hyrëse bashkë me vendin e rojeve.

Nga ndërtesat e brendshme të kohës turke është me interes ndërtesa e madhe qendrore, e cila ka afreske të shek. XVIII si ato të Xhamisë së Tiranës, me motive arkitekturore dhe motive nga Damasku, të cilat vazhdojnë përgjatë një dekorimi linear deri në një sallë të brendshme. Interes paraqet edhe “tyrbja” e Teqes së Dollmës, e cila mendoj është gjëja më me vlerë në Shqipëri e Periudhës Osmane, në aspektin arkitekturor dhe atë të pikturës. 
Kullë vrojtuese e kalasë së Krujës (marrë nga një vepër tjetër e S.Bettinit)

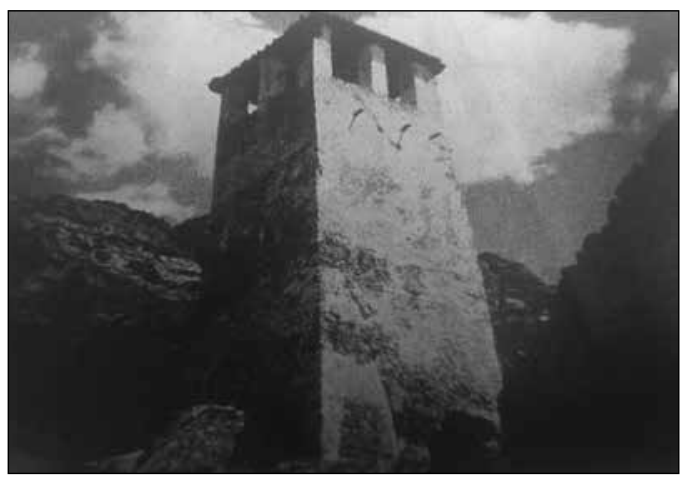

Propozim: në një të ardhme, kur të mendohet të restaurohet kompleksi, propozoj të ndërtohen dhe të ngrihen disa fragmente muresh, të vihet në funksionim porta e hyrjes, të pastrohet dhe të restaurohet ndërtesa qëndrore, e cila mund të kthehet në një muze të vogël për objekte të gjetura në këtë krahinë.

\section{Rubik}

Nga kisha e Shën Shpëtimtarit në Rubik vetëm pjesa e absidës është antike (shek. XIII), absida e vogël gjysmërrethore me tre dritare me afreskë brenda. Kisha është restauruar së voni, duke përfshirë edhe absidën e vogël dhe pjesë të sanktuarit të kishës antike. Dyshemeja është e ngritur duke fshehur gjysmën e mirë të afreskëve të figurave të shenjtëve në regjistrin e poshtëm të sanktuarit. Pjesa tjetër është e mbuluar nga boja, por ka shumë mundësi që nga gërryerja e bojës mund të nxjirren në pah pjesë të tjera të afreskut. Pjesa antike paraqet interes arkitekturor për stilin e saj romak-gotik dhe elementë si ato që gjenden në kishat normane të Kalabrisë, gjë që tregon një lidhje të ngushtë me ndërtesat e anës tjetër të Adriatikut.

Padyshim pjesa më me interes është piktura dekorative, e ndarë në tre regjistra të mbivendosur:

konka: Deisis me dhuruesit

regjistër i mesëm midis dritareve: Liturgjia Hyjnore me figura dhuruesish (një prift dhe një fetar tjetër, pak i dukshëm). Pranë abatit shkrimi që jep datën e rëndësishme, të paimagjinueshmen $1250^{1}$.

1 Kjo datë korigjon idenë e dhënë edhe nga Rey e 1472. Kisha eksistonte më shek. XIII, e konfirmuar nga një dokument i publikuar nga Valentini e Cordignano, të vitit 1269, në të cilin abati Dimitri i Shën Shpetimtarintë Rubikut jepte lajme rreth disa princave të asaj kohe. 


\section{Albanon}

\section{Revistë kulturore}

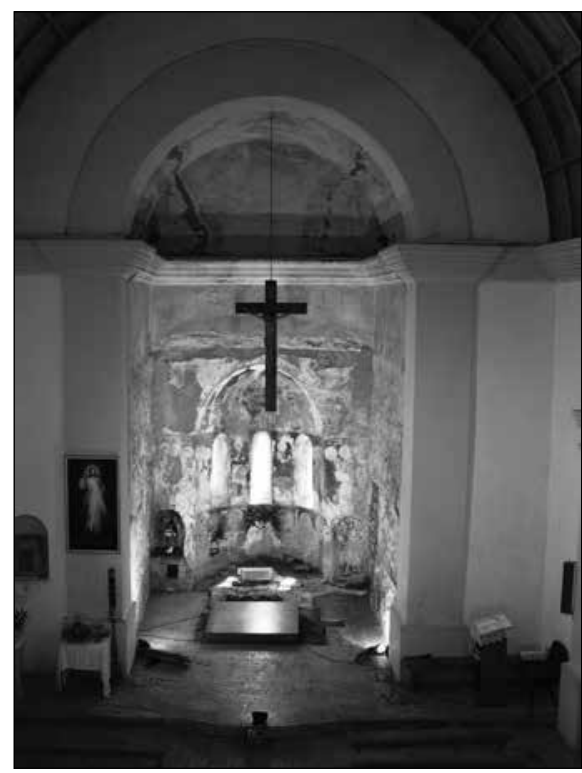

Kisha e Shën Shpëtimtarit, Rubik (marrë nga interneti)

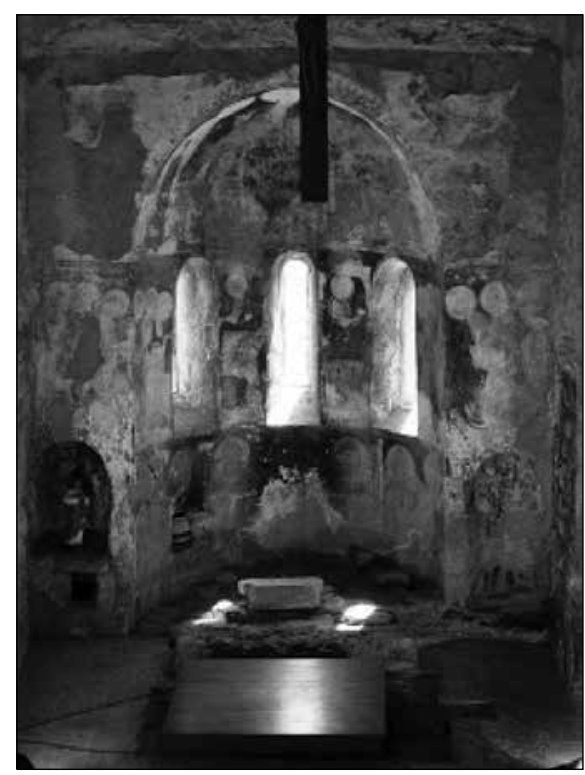

Absida e kishës së Shën Shpëtimtarit, Rubik (marrë nga interneti)

regjistri i ulët: Shenjtorë me figura të plota, midis tyre shenjtori shqiptar Asti.

Shkrimet që shoqërojnë figurat (përveç siglave tradicionale) dhe ato të ofertës janë të gjitha latinisht.

mbi hark: Lajmërimi

Këto piktura paraqesin një rëndësi të madhe për datimin e tyre dhe stilin romanik e jo bizantin, gjë që shfaq lidhje me pikturat e kriptës së Aquileia-s. Për këto piktura kam ndërmend të flas në kongresin e ardhshëm të Institutit.

Propozim: të bëhet me shumë kujdes konservimi i veprës.

\section{Balldren}

Asgjë për të shtuar nga sa njihet: duhet kushtuar vëmendje vetëm formës së bazilikës së kishës që është qartësisht perëndimore. Ekziston mbishkrimi latinisht, leximi i tij nga Ippen-it nuk më duket i saktë. Ippen, mendoj unë, ka lexuar Perlatai (Përlatët) aty ku është shkruar Presbiterum Lazarum. Sipas mendimit tim duhet lexuar në këtë mënyrë:

Memento Domine fumulum tuum presbiterun Lazarum cum omnibus suis am(icis). 


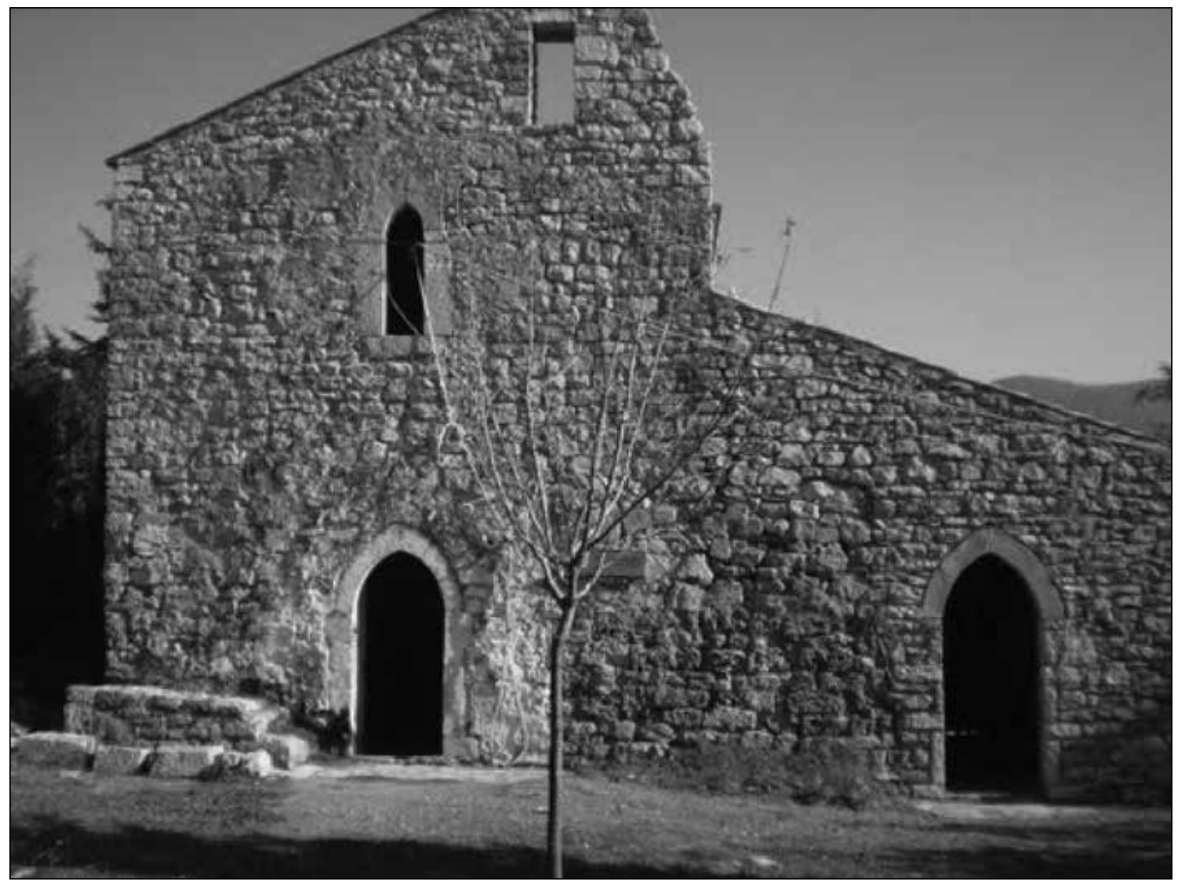

Kisha e Shna Prendës, Balldren (marrë nga interneti)

Kujtohu o Zot për shërbërtorin tënd priftin Lazar dhe miqtë e tij.

Propozim: kisha është në gjendje të mirë, ka nevojë për një pastrim.

\section{Kakarriq}

Kisha është e restauruar e gjitha nga jashtë. Në brendësi ruan akoma struktura që mund të jenë të shek. XIV. Sistemi i rrallë i harqeve përgjatë mureve anësore, mund të gjendet sa kam dijeni, në disa kisha të Dalmacisë. Megjithatë stili i përdorur është qartësisht perëndimor.

Propozim: vetëm të pastrohet më shumë. 